\title{
Archaeoastronomy and ethnoastronomy in the Ryukyu Islands: a preliminary report
}

\author{
Akira Goto \\ Anthropological Institute, Nanzan University, \\ 18 Yamazato-cho, Showa-ku, Nagoya 466-8673, Japan \\ email: agoto@nanzan-u.ac.jp
}

\begin{abstract}
The Ryukyu (Okinawa) Islands are situated in sub-tropical zone between the Japanese Archipelago and Taiwan. Although Okinawan people have a rich tradition of star lore, few studies have been undertaken on its relevance to subsistence, religion and the socio-political system. This paper is a first attempt to explore a systematic relationship between star lore (e.g. relating to the Pleiades) with agriculture, fishing, navigation and religious practice. This paper also considers the possibility of interpreting the nature of prehistoric and historical stone structures from the viewpoint of archaeoastronomy. This kind of analysis is likely to be fruitful, since the kingship of the Ryukyu Islands was strongly associated with sun worship.
\end{abstract}

Keywords. Ryukyu Islands, Okinawa, Japan, Ryukyu kingdom, sun worship, Pleiades, solstice

\section{A background from the Pacific Islands}

Cultural astronomy is important in the Pacific Islands, because Pacific islanders are known for their rich tradition of star lore and astronomical knowledge. One example is navigation by the stars. Among the Caroline Islanders of Micronesia (almost uniquely), traditional navigation continues to be maintained even today. Their navigational technique involves the integrated use of observations of different natural phenomena such as stars, winds, swells, and birds, but the core of their navigation is the 'star compass'.

On Puluwat Island, Altair is considered the greatest of all the navigation stars. It is the starting point for the count of stars in the star chart used for navigation. Although it actually rises and sets $7^{\circ}$ north of the equator, Puluwat is also $7^{\circ}$ north, so Altair always bears true east or west. It is associated with a mythological bird, 'Big Bird', that dominates the sky (Gladwin 1970). Puluwat Islanders used to sail to the west to pay tribute to the Yap Empire. Since their main sailing direction was between west and east, Altair was the guiding star for their long voyage in the east-west direction.

As a result of two types of factor, geographical (e.g. the latitude of the islands and the fact that the islands are surrounded by the sea) and socio-cultural (i.e. the continuous voyages to the west and east respectively for the tribute to the Yap Empire and the return sailing), observations of the rising and setting of Altair over the sea horizon are of key importance in Puluwat.

It is clear that cultural astronomers need to develop an integrated view on astronomical knowledge, geography, cosmology, myths, subsistence activities, navigational techniques, the season for navigation, and so on. The purpose of this paper is to start to develop an integrated view of this kind regarding the astronomical knowledge of people on the subtropical islands of Ryukyu. 


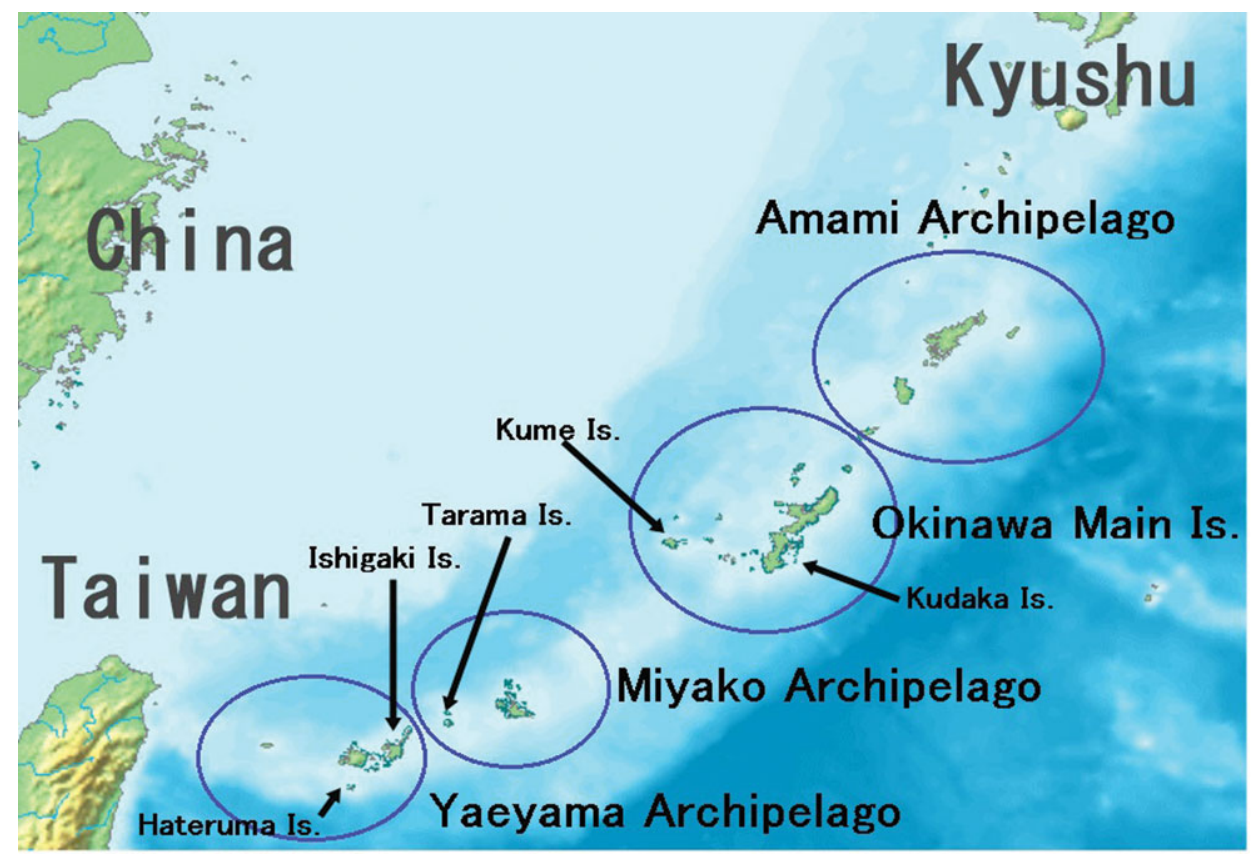

Figure 1. Map of the Ryukyu Islands showing the islands mentioned in the text.

\section{The culture of the Ryukyu Islands}

The Ryukyu or Okinawa Islands lie at the southern end of Japan, between Kyushu Island and Taiwan. They are divided into four regions, which, listed from north to south, are Amami Archipelago, Okinawa Main Island, Miyako Archipelago, and Yaeyama Archipelago (Fig. 1). The Miyako and Yaeyama Archipelagos are sometimes grouped together as the Sakishima Islands, meaning 'islands at the far end'.

The Ryukyu Islands have been influenced by both Japan and China. Under these influences, there formed an independent Ryukyu kingdom, which retained its independence until the beginning of the 17 th century when the islands were subordinated by the Tokugawa Government Regime. Before the subordination, the Ryukyu kingdom prospered by trade with China, Korea and southeast Asia.

The political structure of the Ryukyu kingdom can be characterized as a dual kingship in which men governed political matters while women played a central role in religious ones. The Kikoe-no-ookimi, the most sacred official shaman, was a close female relative of the king. Under this sacred shaman there existed a hierarchy of religious officials, called noro, throughout the kingdom. They were all women.

A key aspect of Ryukyu Island religion is that there was little influence from either Buddhism or Shintoism. Thus, for instance, forms of burial on the Ryukyu Islands were totally different from those of Buddhistic burials in Japan. The Okinawan type of large burial is often called a 'turtle shell' burial and its original form came from southern China, but the people seem originally to have used natural caves, and the most primitive form is a cave burial.

In 1868, the new Meiji Government succeeded the Tokugawa Government after the civil war. At the end of the 19th century, the Meiji Government forced the Okinawan people to adopt Shintoism, but the people continued to practice traditional religion based on shamanism and still do so today. For example, while traditional 'utaki' shrines built today typically have a Shinto symbolic entrance placed in front of them, the interior has 
not changed. At the very end of the utaki shrine is the most sacred zone where only shamans are allowed to enter. In this zone there is usually a sacred incense burner and a sacred rock which is the chair of the sacred spirit.

Because of the limited influence of Buddhism and Shintoism, traditional beliefs and oral history in the Ryukyu Islands may retain some ancient elements of Japanese culture before the influence of Buddhism. The Sakishima Islands, in particular, are connected to Taiwan, a sort of 'doorway' to the Austronesian homeland. Evidence from archaeology, linguistics and mythology all point to possible Austronesian influences in the Sakishima Islands (e.g. Goto 2010).

\section{Star lore}

Before the introduction of the Chinese calendar and Feng Shui, probably in the 17th century, Ryukyu islanders mainly used celestial and natural phenomena to tell the season and predict the weather for agriculture and fishing. Since the Ryukyu Islands lie in the northern hemisphere, the Pole Star was an important indicator of direction. According to a folk song:

Boats sailing during the night-time use the polar star as a direction mark,

Parents living their life use their children as a direction mark.

Even after the introduction of the Chinese system, the indigenous system seems to have been maintained in the more remote islands. An example is the discovery of the 'Book of How to Observe the Stars' (or 'Star Book') on Tarama Island in the Miyako Archipelago (Fig. 2). This document records the way to define the season and predict the weather by observing various stars (Tarama Village 1993: 331-340). Similar documents have been reported in other remote islands such as Kume Island (west of Okinawa Main Island) and Hateruma Island in the Yaeyama Archipelago. There are also many known proverbs and considerable folk knowledge concerning the prediction of the weather by observing stars (e.g. Iwasaki 1974).

In addition, a star chart has been reported from Hateruma Island in the Yaeyama Archipelago, the southernmost of the Ryukyu Islands. From this island, one can see the upper three stars of the Southern Cross, which were used to define the season. Looking at the star chart, it is clear that the stars were used to indicate twelve points evenly spaced around the compass, including the cardinal directions (Fig. 3). Each of these twelve points is associated with an animal: north is Mouse, south is Horse, and so on. These twelve animals are also associated with the division of time within a day: Mouse is midnight, Horse is noon, etc. These twelve animals also correspond to the 12-year cycle by which the year 2011 is the year of the rabbit, 2012 is the year of the dragon, and so on.

This twelve-unit system is a modification of the Chinese zodiac system, one similar to which was also used in Japan. We can hypothesize that the Ryukyu islanders were used to observing the rising and setting points of particular stars in the manner of a 'star compass' similar to that used in Micronesia.

Examining the star book and star chart together, we notice that the rising and setting of stars was also used to indicate the season, although there are some ambiguities as to whether the stars were observed at sunset or sunrise. Expressions such as 'when the star is first visible' or 'when the star is last visible' certainly indicate that the Ryukyu islanders observed stars in order to know the season (Kuroshima 1999). In addition, expressions such as a-ri yudon or agari-yudon are interpreted as meaning heliacal rise, while iri-yudon is interpreted as helical set. Here agari means 'rise' and iri means 'set', while yudon means 'stagnated' or 'less visible'. 


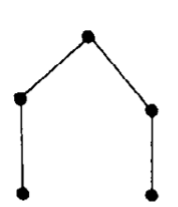

（図 4 ）箕星

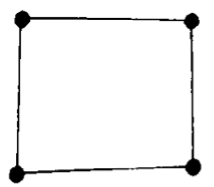

（図 8) 大ョサシ

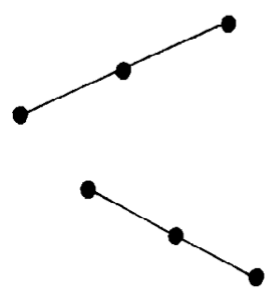

（図12）立明星

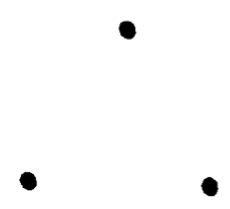

（図16）カホシ星

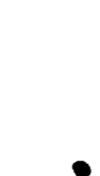

(図20)ウブラ星

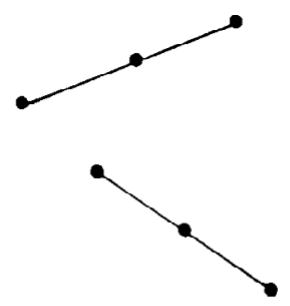

（図 3）立明星

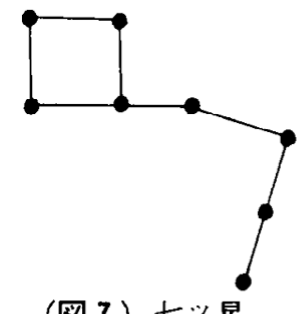

（図 7 ）七ッ星

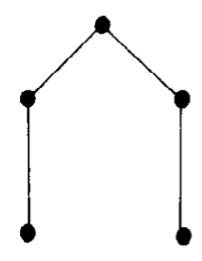

（図11）箕星

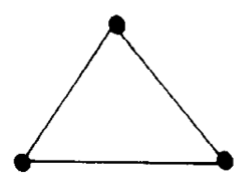

（図15）ヨイ星

（図19）夕夕キ星

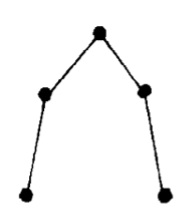

（図 2 ）箕星

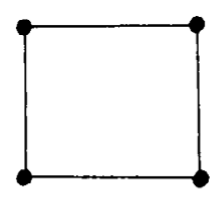

（図 6) 小ヨサシ星

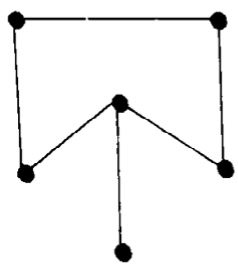

（図10）六ッ星

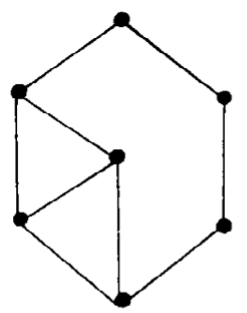

（図 1）六ッ星

（図 5）南風見星

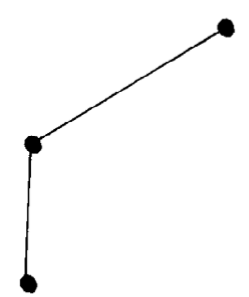

（図 9) カボシ星

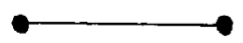

（図14）四差星

(図13) 大ウブラ・小ウブラ

（図18）マイシ星

Figure 2. The 'Star Book' on Tarama Island (after Tarama Village 1993: 334). 


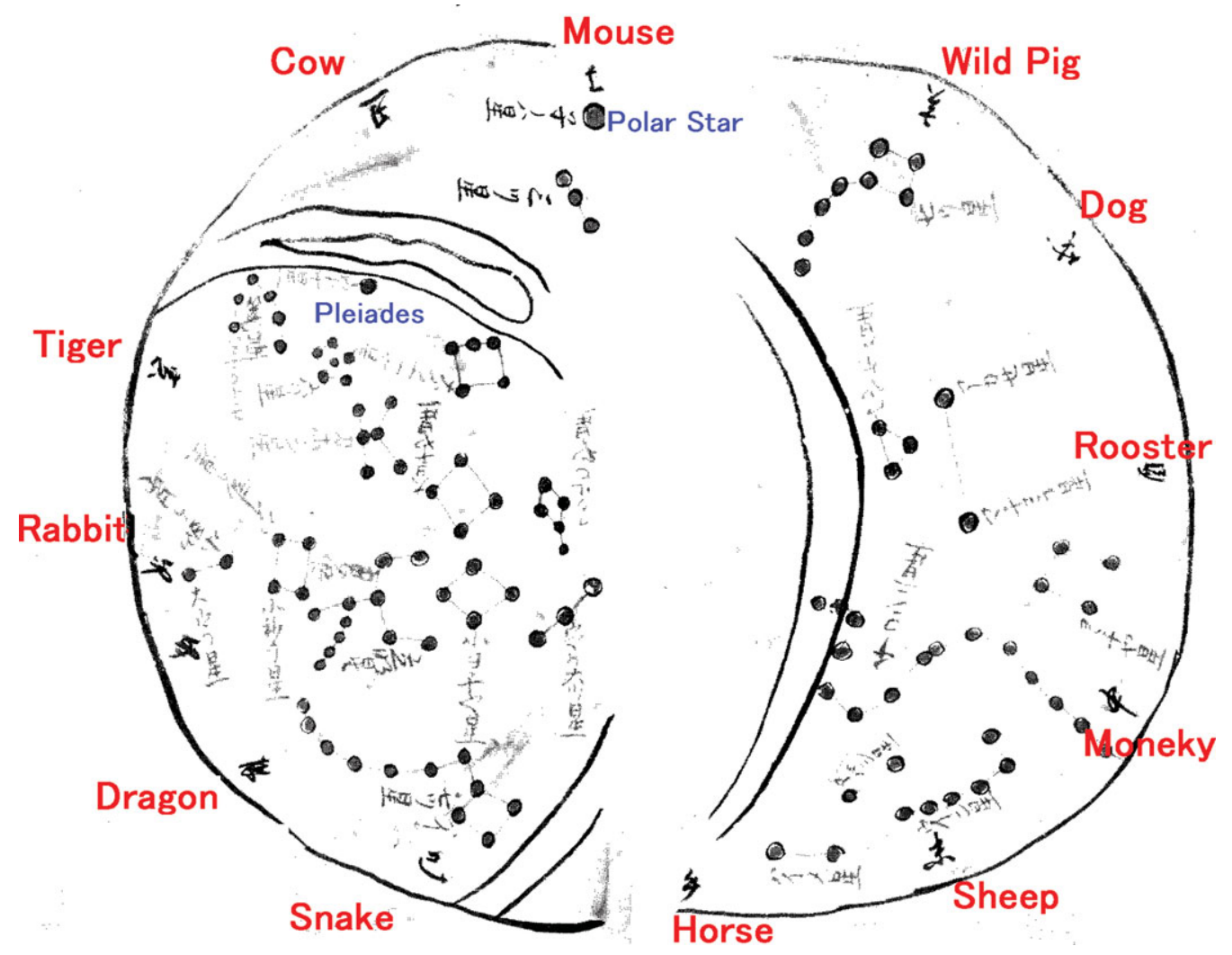

Figure 3. The star chart from Hateruma Island (after Kuroshima 1999: 43).

\section{Stones for observing the Pleiades}

\subsection{The Pleiades in the Ryukyu Islands}

Of the many constellations seen in the islands, the Pleiades is the most important. It is called murika-bushi or muri-bushi, 'clustered stars'. Among the many myths and legends concerning the Pleiades is the following:

Seven ladies descended from the heavens to the earth to bathe. A fisherman who spied them hid the clothes of one of the ladies and then forced her to be his wife. Later she discovered that her husband had stolen her clothes, and finally she ascended to the sky and returned to her sisters. They are now seen as the Pleiades in the sky.

The following folktale also concerns the Pleiades:

The farmers on Yaeyama Archipelago had been subject for many years to a heavy land tax collected by government officials. Seeing that this was not right, the king of the Heavens ordered the Northern Seven Stars to rule the Yaeyama Archipelago. However, because the stars did not obey the king, the stars were banished to Northern Sky. After this, the king of the Heavens ordered the Southern Seven Stars to rule the islands. However these stars would not follow the king's orders either, so they were banished to the Southern Sky.

The king of the Heavens was very angry, and all of the stars felt frightened. Then the constellation of little stars, Murikabushi, went before the King and said "I will do the job". The king was pleased, and ordered them to pass through the center of the sky. For this reason, Murikabushi rises from the East Sea, passes through the center of the sky of the Yaeyama Archipelago, and sets in the West Sea.

After that, the farmers were able to schedule the work on the farm by observing the position of these stars in the sky every evening, and knew the times for sowing and 
harvesting to get good crops. The song of Murikabushi-yunta, 'the song of the Pleiades', was always sung by farmers returning home after working on their farms. The farmers would always say that their village was rich because they were able to know the times to sow and harvest wheat by observing the position of the Murikabushi stars (Yokoo \& Miyaji 2007).

\subsection{Star-observing stones}

The Pleiades were conceived as a zenith star in the Yaeyama Archipelago and their rise indicated the season for planting crops such as wheat and foxtail millet. In the Yaeyama Archipelago, stones were erected for observing the altitude of the Pleiades. The stone in Kohama Island is called shiti-sadame-ishi, 'season-defining stone' or 'stone for defining the season', and those in Ishigaki Island and Taketomi Island (Fig. 4) are called hoshi-mi$i s i$, 'star-observing stone' or 'stone for observing a star'. People sat in front of the stone and observed the altitude of the Pleiades using its top or through the hole in it. The observation was made about November when the Pleiades appear in the eastern horizon at twilight. When the Pleiades reached a certain altitude at twilight in the eastern sky, farmers started to sow wheat. This practice is reminiscent of a similar custom in the Gilbert Islands, Micronesia (Hilder 1959).

\subsection{A Pleiades shrine}

Among hundreds of utaki, religious shrines, in the Ryukyu Islands is one called Muribushiutaki, or the Pleiades shrine. This was constructed for worshiping the Pleiades. Concerning the origin of this shrine, there is a legend:

One night, a girl of good behavior saw a light descending from the Pleiades. Every night she saw the same strange phenomenon. The people were so impressed with this that they finally went out to find out what it was. They found a circular mark of white sand on the ground. Believing that was where gods descended from the heavens, they constructed a shrine for the worship of the Pleiades as a god of fertility.

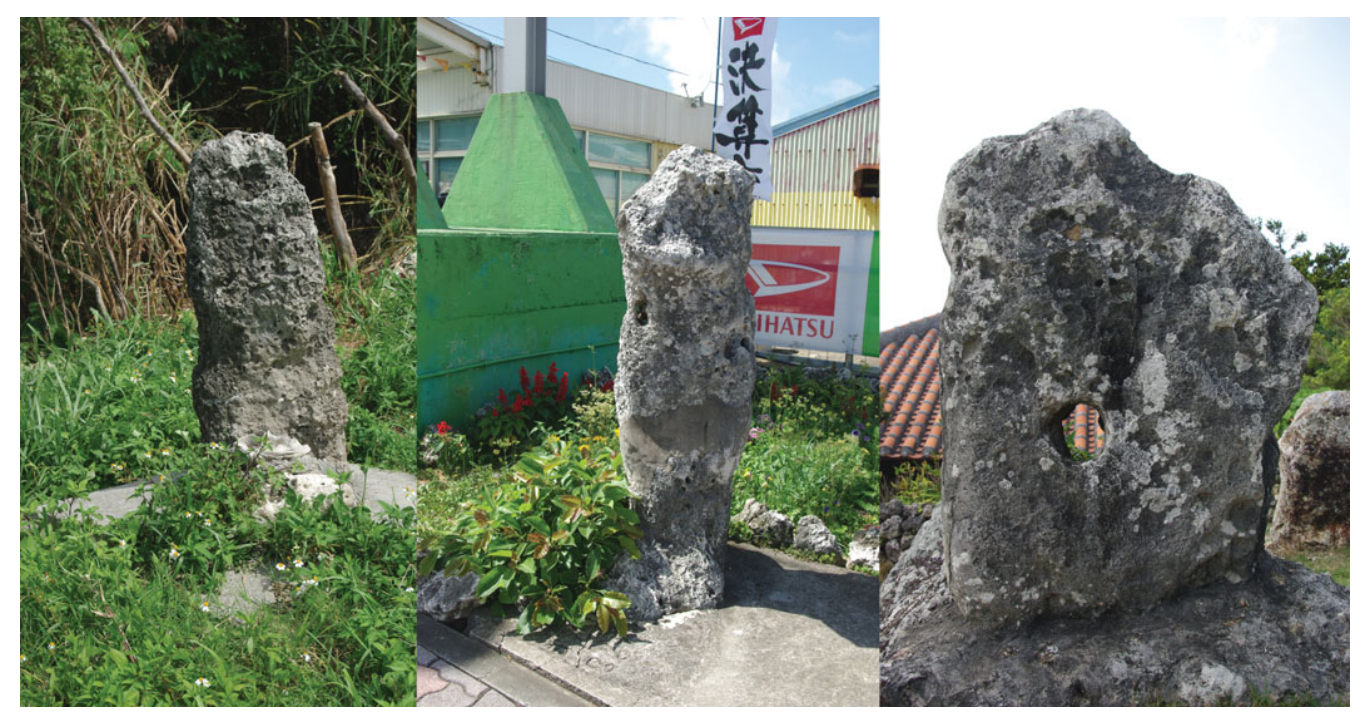

Figure 4. Star-observing stones on Ishigaki Island (left \& middle) and Taketomi Island (right). 

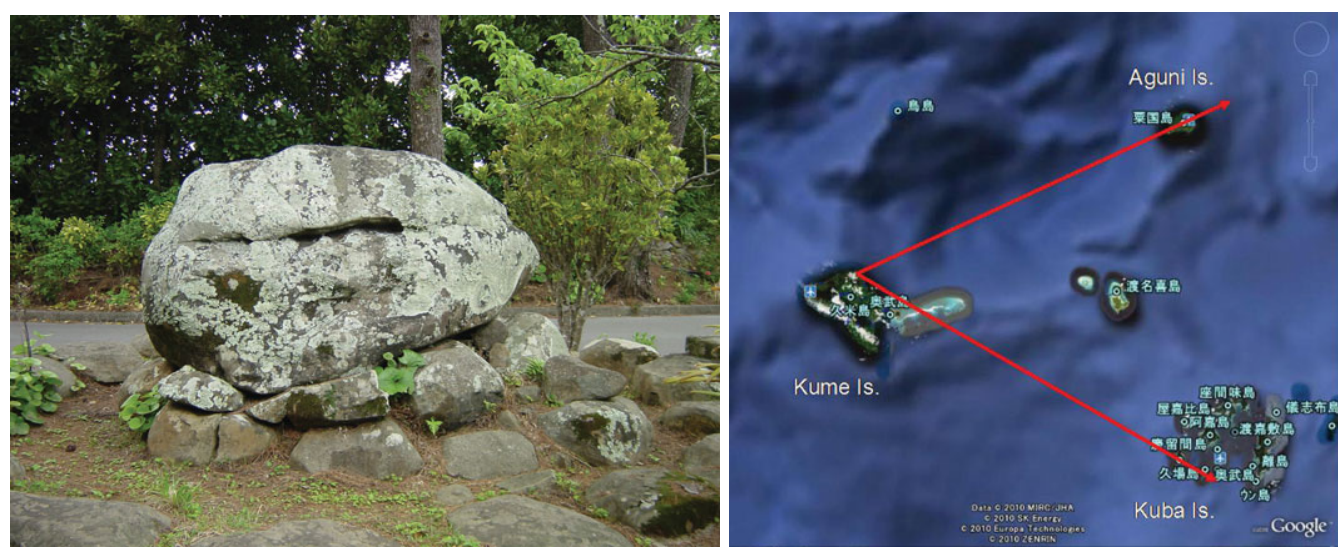

Figure 5. Left: The sun stone on Kume Island. Right: The solstitial sunrise alignments from the sun stone.

\section{The sun}

\subsection{A sun stone}

Kume Island, where one of the star books has been found, lies at an important location on the trade route between the capital city, Shuri, and China. A high-status man called Donohiya is known about on this island. He may have been a kind of chief, but according to legends he went to China and learned calendrics and astronomy. Donohiya was a specialist in astronomy and navigation and led the people by predicting the weather and seasons. This practice is called Uteda-ugmi, meaning to worship or observe the sun.

On Kume Island, there is an uteda-ishi, or 'sun stone' (Fig. 5 left). Legend has it that Donohiya used this stone to measure the orbit of the sun. There are grooves on this stone, which seem to point to the rising position of the sun at certain times of the year. Nakahara (1990), in particular, mentions the location of this stone - at the northernmost peninsula of the island, far from Donohiya's residence. The reason is that this was an ideal position from which to observe the June and December solstices. From this point, the June solstice sun rises exactly behind Aguni Island, while the December solstice sun rises behind Kuba Island (Fig. 5 right).

This method of observing the rising/setting position of the sun by extending lines from certain structures on the land to islands in the sea is also used in Hawai' $\mathrm{i}$ and other Polynesian islands (Ruggles 1999, Kirch 2004).

\subsection{The sun in the Gusuku Period}

The gusuku, 'castle', is one of the characteristic archaeological structures in the Ryukyu Islands. The Gusuku Period began in about the mid-12th century and ended at the beginning of the 17th century when the Ryukyu Kingdom was annexed by the Shimazu Clan of Kyushu. In the 13th and 14th centuries, local chiefs competed with each other both by war between themselves and by trade with China and Southeast Asian countries. These small polities were grouped into three chiefdoms - the Northern, Central, and Southern Chiefdoms - around the 14th century. By the early part of the 15th century, the Sho Dynasty from the Central Chiefdom had succeeded in uniting the islands. The ruling chiefs originally came from the Urasoe area but moved the political center into Shuri, where the largest gusuku, Shuri Castle, was constructed as a royal palace (Fig. 6).

There is enormous variation in the shape and structure of gusuku sites, but they always contain a sacred place or altar, and these sacred places are still worshiped today. There 

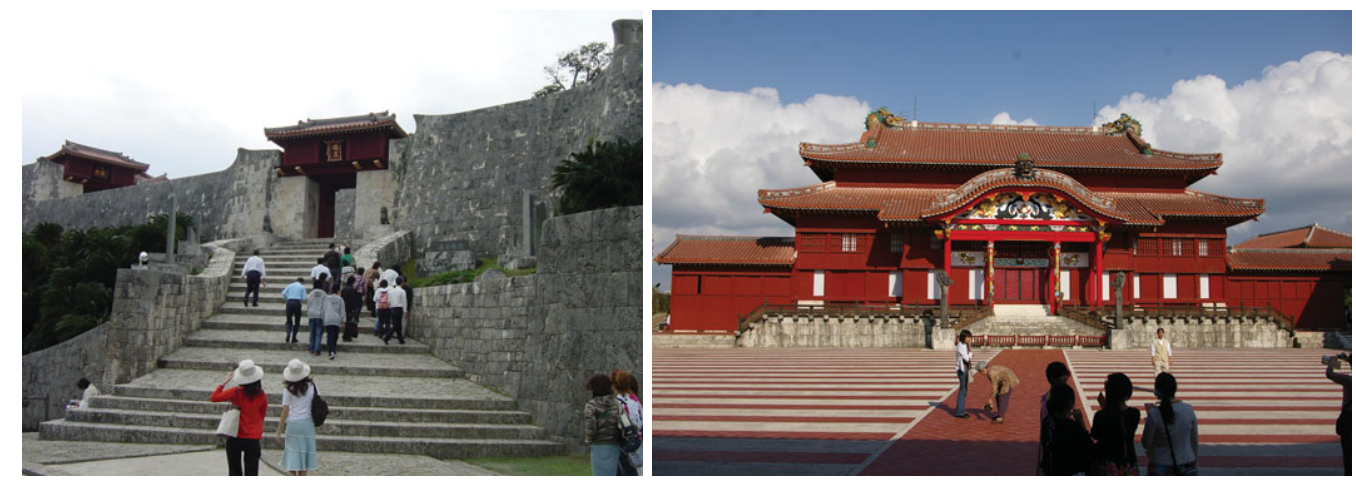

Figure 6. Shuri Castle. Left: the Kankaimon gate; Right: the main palace.

are several possibilities as to the origin of the gusuku, but it is probable that a place that was originally of sacred character gradually came to have an economic and later militaristic role.

As already mentioned, the Ryukyu Kingdom was characterized by its dual structure, with the political leader being male and the religious leader female. In the Omoro-Soshi, a collection of chants probably from the 16th century, there are many chants that associate the king with the sun god:

Chant 1

$\begin{array}{lll}\text { shuri no teda to / tenn ni teru tedato } & \text { / madijyuni chiyoware } \\ \text { (shuri/in/sun and) (heaven/in/shining sun/too) (be united/as a whole) }\end{array}$

Translation: The sun in Shuri [i.e. the king] and the sun in heaven should be united together.

\title{
Chant 2
}

\author{
shuri owaru, tedakoka / tama, isigaki, kerahete \\ (shuri/live/child of the sun) (stone wall/built)
}

Translation: In Shuri Castle lives a child of the sun [king] who built a beautiful stone wall.

These clearly indicate the central role played by sun worship in the kingdom's rituals.

\subsection{The gates of the gusuku}

In the Omoro-Sosh $i$ we find several chants stating that gusuku gates were constructed to face east. For example (only the translation is shown):

In famous Naka Gusuku Castle, / a plank gate was re-built toward the eastern direction.

In renowned Naka Gusuku Castle, / (a gate was re-built) toward the sun's hole.

Nakagusuku castle is one of the great gusuku, constructed in about the 15th century (Fig. 7). The expression in the chant is aragui-ni-mukete, which can be translated as 'directed toward east', but agarui literally means 'rising (of the sun)'. This does not mean true east. For example, the gate that was 're-built' seems to be the one opened in the wall of the additional square of the castle, then newly built. This gate opens to the ENE, facing sunrise at the June solstice.

The same is true of the gusuku at Itokazu, Chinen and Tama, all of whose gates were directed toward the ENE. A special mention should be made of Tama Castle. Gusuku gates were usually constructed by piling up square rocks, but the one at Tama was made by drilling a hole in a huge rock (Fig. 8). It would surely have been much easier to make a gate by piling up rocks to avoid this obstacle. This artificial hole into the rock is oriented 
toward June solstice, and I suggest it is related to the belief in teda-ga-ana, 'the sun's hole in the eastern sea'. In the Omoro-Sohi we find such expressions as: agarui kogane ana / agarui no mashita-ni / teda-ga-ana no mashita-ni
(east/golden hole) (east/right under / sun of hole just under)

Many chants say that the female shaman introduced sunlight into the sacred place within the castle. I interpret these chants as follows: the noro (sacred female shaman) introduced sezi (sacred power; a similar concept to Polynesian mana), symbolized by sunlight, into the sacred place, $i b i$, for the fertility of the kingdom.

The gates facing June solstice sunrise were not built originally in this manner but usually 're-built'. This implies that at a certain time in history, probably after the unification of the islands by the central chiefdom, a reformation of religious thought occurred. This may have been related to the re-structuring of local beliefs by the 'royal' cosmology of the Ryukyu Kingdom.

The above discussion does not mean that the June solstice was more important than the December solstice. On the contrary, there are indications that the December solstice was also a time of importance - the time when the King was re-born. Kojima (1987) considered that from the sacred rock at Urazoe Castle, where the royal family originated, Kudaka Island was worshiped: this island lies in the direction of December solstice sunrise. Kudaka Island, the most sacred of the Ryukyu Islands, is said to be the place where wheat originated. Special altars for the worship of Kudaka Island were placed in many gusuku, including Shuri.
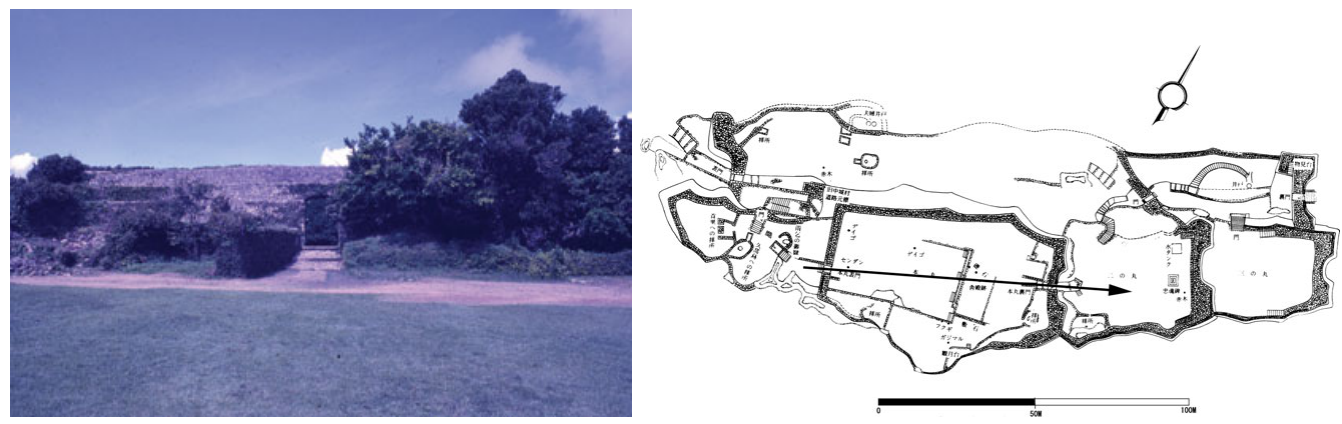

Figure 7. Nakagusuku Castle. Left: view; Right: plan.

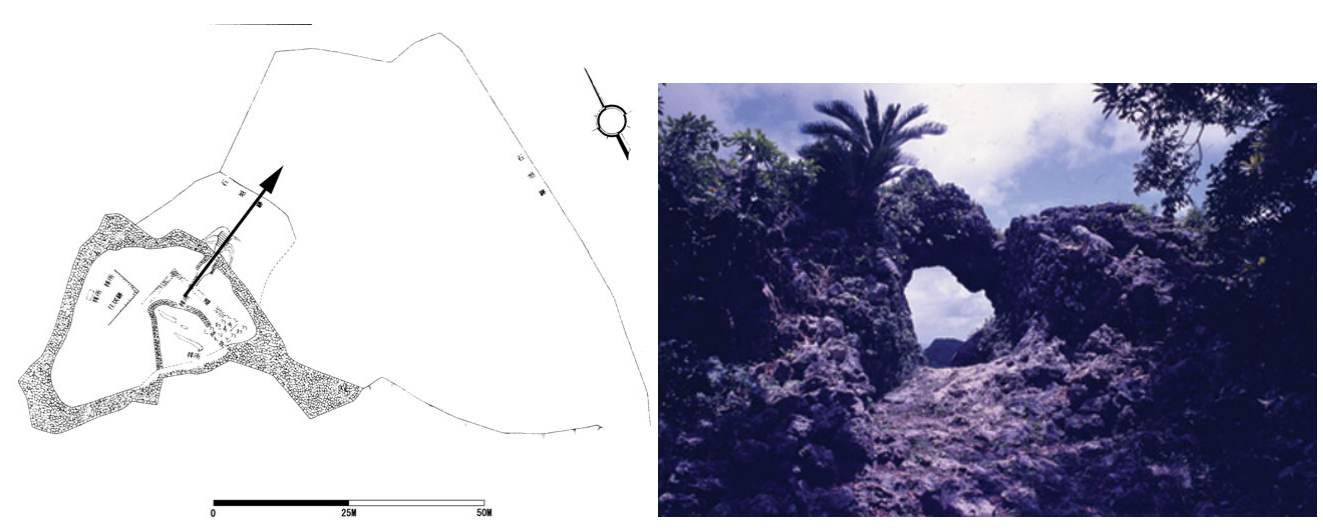

Figure 8. Tama Castle. Left: plan; Right: gate. 
Kojima (1987) and Suetsugu (1995) also consider that the king's annual ceremonial tour of the southeastern coast of the island, the agari-umai ('east-round'), was related to sun ritual. This tour, made together with the sacred women, the kikoe-no-ookimi, was to the area where most of the castles with gates facing June solstice sunrise are located. The tour also had the purpose of worshiping Kudaka Island, whence the first light of the rising sun appears at December solstice. It is too early to make a conclusive argument, but the concentration of archaeological remains relevant to sun ritual in this small area argues strongly that both the June and December solstices were important in the royal rituals of the Ryukyu Kingdom.

\section{Conclusion}

Although I can not go into detail in this short report, it should be mentioned that there also exist many beliefs and rituals concerning the moon and eclipses: for example, the king as a sun god had to change his clothing during a solar eclipse. This preliminary report has simply offered some possible connections between astronomical phenomena and cultural practices. It has certainly shown, however, that the Ryukyu Islands are a rich field for promoting research in cultural astronomy. Since these islands are situated in an ecological setting similar to that of the tropical islands in the Pacific, comparative research on the practical use of astronomical phenomena will be fruitful. Further comparisons should also be made with other areas at a similar latitude, such as Hawai'i and Middle America.

\section{References}

Gladwin, T. 1970, East is a Big Bird: Navigation and Logic on Puluwat Atoll, Harvard University Press, Cambridge MA.

Goto, A. 2010, Mythicization of tsunami in the Ryukyu Islands: a process of seascape formation in island societies. In P. Wallin and H. Martisson-Wallin (eds), Selected Papers from the VII International Conference on Easter Island and the Pacific: Migration, Identity, and Cultural Heritage, Gotland University, Visby, pp. 465-471.

Hilder, B. 1959, Polynesian navigational stones. Journal of the Institute of Navigation 12, 90-97. Iwasaki, T. 1974, Collected Papers of Takuji Iwasaki, Dento to Gendai, Tokyo [in Japanese].

Kirch, P. V. 2004, Solstice observation in Mangareva, French Polynesia: new perspectives from archaeology. Archaeoastronomy. The Journal of Astronomy in Culture, 18, 1-19.

Kojima, Y. 1987, Shuri Castle: gods supporting kingship. In K. Tanigawa (ed.), Gods in Japan, Vol. 13, Hakusuisha, Tokyo, pp. 133-167.

Kuroshima, T. 1999, Seizu, Tenkimiyo-no-koto, and Hoshimiyo. Bulletin of the Ishigaki Municap Museum of Yaeyama 16/17, 38-52.

Ruggles, C. L. N. 1999, Astronomy, oral literature, and landscape in ancient Hawai'i. Archaeoastronomy. The Journal of Astronomy in Culture, 14(2), 33-86.

Nakahara, Z. 1990, History and Folklore of Kumejima Island (ed. by Hitoshi Uezu), Daiichi Shobo, Tokyo [in Japanese].

Suetsugu, S. 1995, Kingship and Mythology of the Ryukyu: A Study of Omoro-Soshi, Daiichi Shobo, Tokyo [in Japanese].

Tarama Village, 1993, A History of Tarama Village, Vol.4(3): Folklore, Editorial Board of Village History, Tarama Village, Okinawa.

Yokoo, H. \& Miyaji, T. 2007, On the Star-Observing Stone in Ishigaki Island. A Lecture at the 39th Danten-no-kai, National Astronomical Observatory, Tokyo [in Japanese]. 